Article

\title{
Bending Analysis of Isotropic Rectangular Kirchhoff Plates Subjected to Non-Uniform Heating Using the Fourier Transform Method
}

\author{
Valentin Fogang \\ Civil Engineer, C/o BUNS Sarl, P.O Box 1130, Yaounde, Cameroon; valentin.fogang@bunscameroun.com \\ ORCID iD https://orcid.org/0000-0003-1256-9862
}

\begin{abstract}
The object of this paper is the bending analysis of isotropic rectangular Kirchhoff plates subjected to nonuniform heating (NUH) using the Fourier transform method. The bottom and top surfaces of the plate are assumed to have different changes in temperature, whereas the change in temperature of the mid-surface is zero. According to classical plate theory, the governing equation of the plate contains second derivatives of the NUH; these derivatives are zero by constant value of the NUH, which leads to its absence in the governing equation. This paper presented an approach by which Fourier sine transform was utilized to describe the NUH, while the double trigonometric series of Navier and the simple trigonometric series of Lévy were utilized to describe the deflection curve. Thus, the NUH appeared in the governing equation, which simplified the analysis. Rectangular plates simply supported along all edges were analyzed, bending moments, twisting moments, and deflections being determined. In addition, rectangular plates simply supported along two opposite edges were analyzed; the other edges having various support conditions (free, simply supported, and fixed).
\end{abstract}

Keywords: Isotropic rectangular plate; Kirchhoff-Love plate theory; non-uniform heating; Fourier sine transform; Navier solution; Lévy solution

\section{Introduction}

The Kirchhoff-Love plate theory (KLPT) is a two-dimensional mathematical model that is used to determine the stresses and deformations in thin plates subjected to forces and moments. This theory is an extension of Euler-Bernoulli beam theory and was developed in 1888 by Love using assumptions proposed by Kirchhoff [1]. The KLPT is governed by the Germain-Lagrange plate equation; this equation was first derived by Lagrange in December 1811 in correcting the work of Germain [2] who provided the basis of the theory. For rectangular plates, Navier [3] in 1820 introduced a simple method for the analysis when a plate is simply supported along all edges; the applied load and the deflection were expressed in terms of Fourier components and double trigonometric series, respectively. Another approach was proposed by Lévy [4] in 1899 for rectangular plates simply supported along two opposite edges; the applied load and the deflection were expressed in terms of Fourier components and simple trigonometric series, respectively. Various studies have focused on the bending analysis of plates using the Fourier transform method. Mama et al. [5] solved by the 
method of finite Fourier sine transform the boundary value problem of simply supported rectangular Kirchhoff plates subjected to applied transverse loads. Kamel [6] described the operational properties of the finite Fourier transform method, with the purpose of solving boundary value problems of partial differential equations, which has some applications on potential and steady-state temperature. Mama et al. [7] presented the single finite Fourier sine integral transform method for the flexural analysis of rectangular Kirchhoff plate with opposite edges simply supported, and the other edges clamped for the case of triangular load distribution on the plate domain. Sayyad et al. [8] assessed a trigonometric plate theory for the static bending analysis of plates resting on Winkler elastic foundation; the theory considered the effects of transverse shear and normal strains. Onyia et al. [9] presented the elastic buckling analysis of rectangular thin plates using the single finite Fourier sine integral transform method. Ike [10] presented the double Fourier cosine series method for solving the flexural problem of Kirchhoff plates resting on an elastic foundation of the Winkler type.

In this paper the bending analysis of isotropic rectangular Kirchhoff plates subjected to a non-uniform heating (NUH) was conducted. The Fourier sine transform was utilized to describe the NUH, while the double trigonometric series of Navier and the simple trigonometric series of Lévy were utilized to describe the deflection.

\section{Materials and methods}

\subsection{Governing equations of the plate subjected to non-uniform heatin}

The Kirchhoff-Love plate theory (KLPT) [1] is used for thin plates and shear deformations are not considered. The spatial axis convention $(\mathrm{X}, \mathrm{Y}, \mathrm{Z})$ is represented in figure 1 below.

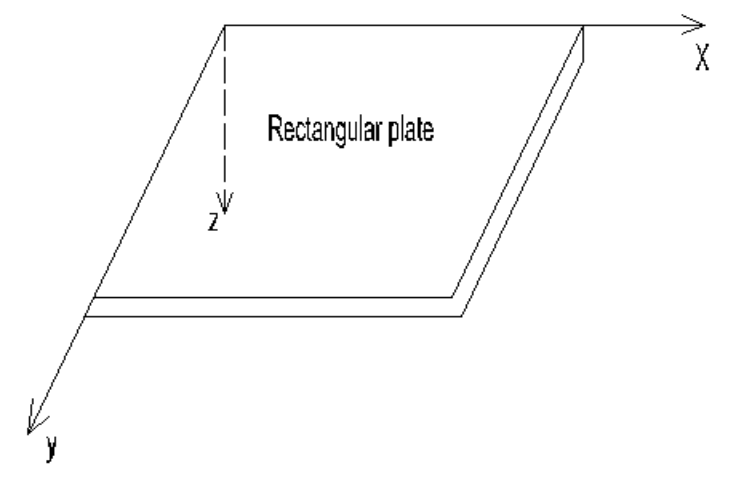

Figure 1. Spatial axis convention $\mathrm{X}, \mathrm{Y}, \mathrm{Z}$

The equations of the present Section are related to the KLPT. Displacements in $\mathrm{x}-, \mathrm{y}-$, and $\mathrm{z}$ - directions are denoted by $\mathrm{u}(x, y, z), \mathrm{v}(x, y, z)$, and $\mathrm{w}(x, y, z)$, respectively, and are given by

$$
u(x, y, z)=-z \frac{\partial w}{\partial x}, \quad v(x, y, z)=-z \frac{\partial w}{\partial y}, \quad w(x, y, z)=w(x, y) . \quad(1 \mathrm{a}, \mathrm{b}, \mathrm{c})
$$

The strains are related to the displacements using Equations (1a-c) as follows:

$\varepsilon_{x x}=\frac{\partial u}{\partial x}=-z \frac{\partial^{2} w}{\partial x^{2}}, \quad \varepsilon_{y y}=\frac{\partial v}{\partial y}=-z \frac{\partial^{2} w}{\partial y^{2}}, \quad \gamma_{x y}=\frac{\partial u}{\partial y}+\frac{\partial v}{\partial x}=-2 z \frac{\partial^{2} w}{\partial x \partial y} . \quad(2 \mathrm{a}, \mathrm{b}, \mathrm{c})$ 
The strains are also related to stresses and NUH as follows:

$(3 \mathrm{a}, \mathrm{b}, \mathrm{c}, \mathrm{d})$

$\varepsilon_{x x}=\frac{\sigma_{x x}}{E}-v \frac{\sigma_{y y}}{E}+\frac{\alpha_{T} \Delta T}{d} z, \quad \varepsilon_{y y}=\frac{\sigma_{y y}}{E}-v \frac{\sigma_{x x}}{E}+\frac{\alpha_{T} \Delta T}{d} z, \quad \gamma_{x y}=\frac{\tau_{x y}}{G}, \quad \kappa_{T}=\frac{\alpha_{T} \Delta T}{d}$,

where $\mathrm{E}$ is the elastic modulus, $v$ is the Poisson's ratio, $\alpha_{\mathrm{T}}$ is the coefficient of thermal expansion, $\Delta \mathrm{T}=\Delta \mathrm{T}_{\mathrm{bs}}-\Delta \mathrm{T}_{\mathrm{ts}}$ is the difference between the temperature changes at bottom surface $\left(\Delta \mathrm{T}_{\mathrm{bs}}\right.$ at $\left.\mathrm{z}=\mathrm{d} / 2\right)$ and top surface $\left(\Delta \mathrm{T}_{\mathrm{ts}}\right.$ at $\mathrm{z}$ $=-\mathrm{d} / 2$ ) of the plate, $\mathrm{d}$ is the plate thickness, and $\kappa_{\mathrm{T}}$ is the thermal curvature strain. The temperature changes are assumed to vary linearly through the plate thickness. Combining Equations (2a-c) and (3a-c) yields

$$
\begin{aligned}
& \sigma_{x x}=-\frac{E z}{1-v^{2}} \times\left(\frac{\partial^{2} w}{\partial x^{2}}+v \frac{\partial^{2} w}{\partial y^{2}}+(1+v) \kappa_{T}\right), \quad \sigma_{y y}=-\frac{E z}{1-v^{2}} \times\left(\frac{\partial^{2} w}{\partial y^{2}}+v \frac{\partial^{2} w}{\partial x^{2}}+(1+v) \kappa_{T}\right), \\
& \tau_{x y}=G \gamma_{x y}=\frac{E}{2(1+v)} \times\left(-2 z \frac{\partial^{2} w}{\partial x \partial y}\right)=-\frac{E z}{(1+v)} \times \frac{\partial^{2} w}{\partial x \partial y}
\end{aligned}
$$

The bending moments per unit length $\mathrm{m}_{\mathrm{xx}}$ and $\mathrm{m}_{\mathrm{yy}}$, and the twisting moments per unit length $\mathrm{m}_{\mathrm{xy}}$, can be expressed using Equations (4a-c) as follows;

$$
\begin{aligned}
& m_{x x}=\int_{-d / 2}^{d / 2} \sigma_{x x} z d z=-D \times\left(\frac{\partial^{2} w}{\partial x^{2}}+v \frac{\partial^{2} w}{\partial y^{2}}+(1+v) \kappa_{T}\right), \\
& m_{y y}=\int_{-d / 2}^{d / 2} \sigma_{y y} z d z=-D \times\left(\frac{\partial^{2} w}{\partial y^{2}}+v \frac{\partial^{2} w}{\partial x^{2}}+(1+v) \kappa_{T}\right), \\
& m_{x y}=\int_{-d / 2}^{d / 2} \tau_{x y} z d z=-D \times(1-v) \times \frac{\partial^{2} w}{\partial x \partial y}, \quad D=\frac{E d^{3}}{12\left(1-v^{2}\right)}
\end{aligned}
$$

where $\mathrm{D}$ is the flexural rigidity of the plate. The governing equation of an isotropic Kirchhoff plate is given by

$$
\frac{\partial^{2} m_{x x}}{\partial x^{2}}+2 \frac{\partial^{2} m_{x y}}{\partial x \partial y}+\frac{\partial^{2} m_{y y}}{\partial y^{2}}=-q(x, y)
$$

where $\mathrm{q}(\mathrm{x}, \mathrm{y})$ denotes the applied transverse load per unit area. Substituting Equations (5a-c) into Equation (6) yields the governing equation of the isotropic plate subjected to a NUH

$$
\frac{\partial^{4} w}{\partial x^{4}}+2 \frac{\partial^{4} w}{\partial x^{2} \partial y^{2}}+\frac{\partial^{4} w}{\partial y^{4}}=-\frac{\partial^{2}(1+v) \kappa_{T}}{\partial x^{2}}-\frac{\partial^{2}(1+v) \kappa_{T}}{\partial y^{2}}
$$

The Kirchhoff shear forces per unit length are introduced to satisfy the boundary and continuity conditions; they combine shear forces and twisting moments, and can be expressed for an isotropic plate as follows:

$$
V_{x}=-D \times\left(\frac{\partial^{3} w}{\partial x^{3}}+(2-v) \frac{\partial^{3} w}{\partial x \partial y^{2}}\right), \quad V_{y}=-D \times\left(\frac{\partial^{3} w}{\partial y^{3}}+(2-v) \frac{\partial^{3} w}{\partial x^{2} \partial y}\right)
$$




\subsection{Rectangular isotropic plate simply supported along all edges}

Let the plate be simply supported along all edges. The plate dimensions in $\mathrm{x}$ - and $\mathrm{y}$-directions are denoted by $\mathrm{a}$ and $\mathrm{b}$, respectively. The solution of Navier [3] which satisfies the boundary conditions is considered for the deflection curve $\mathrm{w}(x, y)$ as follows:

$$
w(x, y)=\sum_{m} \sum_{n} w_{m n} \sin \frac{m \pi x}{a} \sin \frac{n \pi y}{b}
$$

The Fourier sine transform of $(1+v) \kappa_{\mathrm{T}}$ is given by

$$
(1+v) \kappa_{T}=\sum_{m} \sum_{n} \kappa_{T m n} \sin \frac{m \pi x}{a} \sin \frac{n \pi y}{b}, \quad \kappa_{T m n}=\frac{16(1+v) \kappa_{T}}{\pi^{2} m n}
$$

$\mathrm{m}, \mathrm{n}$ being odd numbers.

Substituting Equations (9) and (10a-b) into Equation (7) yields $\mathrm{W}_{\mathrm{mn}}$ and the deflection function as follows:

$$
\begin{aligned}
& w_{m n}=\frac{\kappa_{T m n}}{\left(\frac{m \pi}{a}\right)^{2}+\left(\frac{n \pi}{b}\right)^{2}}, \\
& w(x, y)=\frac{16 a^{2}(1+v) \kappa_{T}}{\pi^{4}} \sum_{m} \sum_{n} \frac{1}{m n} \frac{1}{m^{2}+(n a / b)^{2}} \sin \frac{m \pi x}{a} \sin \frac{n \pi y}{b} .
\end{aligned}
$$

Substituting Equations (9), (10a-b), and (11a) into Equations (5a-c) yields the bending moments $\mathrm{m}_{\mathrm{xx}}$ and $\mathrm{m}_{\mathrm{yy}}$, and the twisting moments $\mathrm{m}_{\mathrm{xy}}$, as follows:

$$
\begin{aligned}
m_{x x}(x, y) & =-D \times \sum_{m} \sum_{n}\left[w_{m n}\left[-\left(\frac{m \pi}{a}\right)^{2}-v\left(\frac{n \pi}{b}\right)^{2}\right]+\kappa_{T m n}\right] \sin \frac{m \pi x}{a} \sin \frac{n \pi y}{b} \\
& =\frac{16(1+v)}{\pi^{2}} D \kappa_{T} \times \sum_{m} \sum_{n} \frac{1}{m n}\left[\frac{m^{2}+v(n a / b)^{2}}{m^{2}+(n a / b)^{2}}-1\right] \sin \frac{m \pi x}{a} \sin \frac{n \pi y}{b}, \\
m_{y y}(x, y) & =\frac{16(1+v)}{\pi^{2}} D \kappa_{T} \times \sum_{m} \sum_{n} \frac{1}{m n}\left[\frac{m^{2}+(n a / b)^{2}}{m^{2}+(n a / b)^{2}}-1\right] \sin \frac{m \pi x}{a} \sin \frac{n \pi y}{b}, \\
m_{x y}(x, y) & =-\frac{16\left(1-v^{2}\right)}{\pi^{2}} D \kappa_{T} \times \sum_{m} \sum_{n} \frac{m^{2} \frac{b}{a}+n^{2} \frac{a}{b}}{a} \cos \frac{m \pi x}{a} \cos \frac{n \pi y}{b} .
\end{aligned}
$$




\subsection{Rectangular isotropic plate simply supported along two opposite edges}

Let the plate be simply supported along the edges $\mathrm{x}=0$ and $\mathrm{x}=\mathrm{a}$. The solution of Lévy [4] which satisfies the boundary conditions is considered for the deflection curve $\mathrm{w}(x, y)$ as follows:

$$
w(x, y)=\sum_{m} F_{m}(y) \sin \frac{m \pi x}{a} .
$$

The Fourier sine transform of $(1+v) \kappa_{T}$ is given by

$$
(1+v) \kappa_{T}=\sum_{m} \kappa_{T m} \sin \frac{m \pi x}{a}, \quad \kappa_{T m}=\frac{4(1+v) \kappa_{T}}{\pi m},
$$

$m$ being an odd number. Substituting Equations (13) and (14a-b) into Equation (7) yields the differential equation

$$
\frac{d^{4} F_{m}(y)}{d y^{4}}-2\left(\frac{m \pi}{a}\right)^{2} \frac{d^{2} F_{m}(y)}{d y^{2}}+\left(\frac{m \pi}{a}\right)^{4} F_{m}(y)=\kappa_{T m}\left(\frac{m \pi}{a}\right)^{2}
$$

The solution of Equation (15) is as follows:

$$
\begin{gathered}
F_{m}(y)=A_{m} \operatorname{ch} \alpha_{m} y+B_{m} \alpha_{m} y \times \operatorname{sh} \alpha_{m} y+C_{m} \operatorname{sh} \alpha_{m} y+D_{m} \alpha_{m} y \times \operatorname{ch} \alpha_{m} y+\frac{\kappa_{T m}}{\alpha_{m}^{2}} \\
\alpha_{m}=\frac{m \pi}{a}
\end{gathered}
$$

where the coefficients $A_{m}, B_{m}, C_{m}$, and $D_{m}$ are determined using the boundary and continuity conditions.

The slope in y-direction is determined using Equations (13), (14a), and (16a-b) as follows:

$$
\begin{aligned}
\frac{\partial w(x, y)}{\partial y} & =\sum_{m} \frac{d F_{m}(y)}{d y} \sin \frac{m \pi x}{a} \\
& =\sum_{m} \alpha_{m}\left[\begin{array}{l}
A_{m} \operatorname{sh} \alpha_{m} y+B_{m}\left(\operatorname{sh} \alpha_{m} y+\alpha_{m} y \times \operatorname{ch} \alpha_{m} y\right)+ \\
C_{m} \operatorname{ch} \alpha_{m} y+D_{m}\left(\operatorname{ch} \alpha_{m} y+\alpha_{m} y \times \operatorname{sh} \alpha_{m} y\right)
\end{array}\right] \sin \frac{m \pi x}{a}
\end{aligned}
$$

Substituting Equations (13) and (14a) into Equations (5a-c) yields the equations of bending moments and twisting moments as follows:

$$
\begin{aligned}
& m_{x x}=-D \times \sum_{m}\left[-\left(\frac{m \pi}{a}\right)^{2} F_{m}(y)+v \frac{d^{2} F_{m}(y)}{d y^{2}}+\kappa_{T m}\right] \sin \frac{m \pi x}{a}, \\
& m_{y y}=-D \times \sum_{m}\left[\frac{d^{2} F_{m}(y)}{d y^{2}}-v\left(\frac{m \pi}{a}\right)^{2} F_{m}(y)+\kappa_{T m}\right] \sin \frac{m \pi x}{a}, \\
& m_{x y}=-D \times(1-v) \times \sum_{m} \frac{m \pi}{a} \frac{d F_{m}(y)}{d y} \cos \frac{m \pi x}{a} .
\end{aligned}
$$


Substituting Equations (16a-b) into Equations (18a-c) yields the bending moments and twisting moments as follows:

$$
\begin{aligned}
& m_{x x}=-D \times \sum_{m} \alpha_{m}^{2}(v-1)\left[\begin{array}{l}
A_{m} \operatorname{ch} \alpha_{m} y+B_{m}\left(\frac{2 v}{v-1} \operatorname{ch} \alpha_{m} y+\alpha_{m} y \times \operatorname{sh} \alpha_{m} y\right)+ \\
C_{m} \operatorname{sh} \alpha_{m} y+D_{m}\left(\frac{2 v}{v-1} \operatorname{sh} \alpha_{m} y+\alpha_{m} y \times \operatorname{ch} \alpha_{m} y\right)
\end{array}\right] \sin \frac{m \pi x}{a}
\end{aligned}
$$

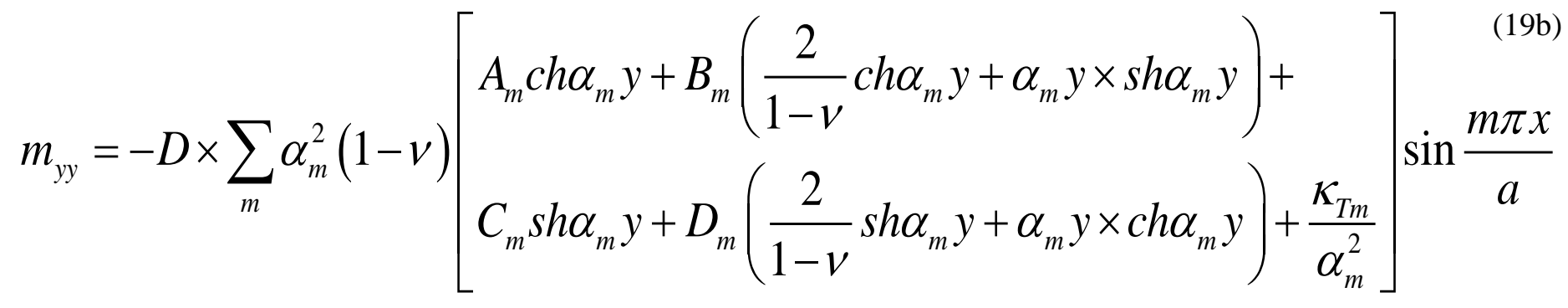

$$
\begin{aligned}
& m_{x y}=-D \times(1-v) \times \sum_{m} \alpha_{m}^{2}\left[\begin{array}{l}
A_{m} \operatorname{sh} \alpha_{m} y+B_{m}\left(\operatorname{sh} \alpha_{m} y+\alpha_{m} y \times \operatorname{ch} \alpha_{m} y\right)+ \\
C_{m} \operatorname{ch} \alpha_{m} y+D_{m}\left(\operatorname{ch} \alpha_{m} y+\alpha_{m} y \times \operatorname{sh} \alpha_{m} y\right)
\end{array}\right] \cos \frac{m \pi x}{a}
\end{aligned}
$$

Substituting Equation (13) into Equation (8b) yields the equation of the Kirchhoff shear forces $\mathrm{V}_{\mathrm{y}}$ as follows:

$$
V_{y}=-D \times \sum_{m}\left[\frac{d^{3} F_{m}(y)}{d y^{3}}-(2-v)\left(\frac{m \pi}{a}\right)^{2} \frac{d F_{m}(y)}{d y}\right] \sin \frac{m \pi x}{a}
$$

Substituting Equations (16a-b) into Equation (20) yields the Kirchhoff shear forces $\mathrm{V}_{\mathrm{y}}$ as follows:

$$
V_{y}=-D \times \sum_{m} \alpha_{m}^{3}(v-1)\left[\begin{array}{l}
A_{m} \operatorname{sh} \alpha_{m} y+B_{m}\left(\frac{v+1}{v-1} \operatorname{sh} \alpha_{m} y+\alpha_{m} y \times \operatorname{ch} \alpha_{m} y\right)+ \\
C_{m} \operatorname{ch} \alpha_{m} y+D_{m}\left(\frac{v+1}{v-1} \operatorname{ch} \alpha_{m} y+\alpha_{m} y \times \operatorname{sh} \alpha_{m} y\right)
\end{array}\right] \sin \frac{m \pi x}{a}
$$

The closed-form expressions of deflection (Equation (16a-b)), slope (Equation (17)), bending moment $\mathrm{m}_{\mathrm{yy}}$ ((Equation (19b)), and Kirchhoff shear forces $\mathrm{V}_{\mathrm{y}}$ (Equation (21)), enable satisfying the boundary conditions along the edges $\mathrm{y}=0$ and $y=b$, leading to the determination of the coefficients $A_{m}, B_{m}, C_{m}$, and $D_{m}$. The bending moments, twisting moments, and displacements are calculated using Equations (19a-b), Equation (19c), and Equations (13), (14b), and (16a-b), respectively. 


\section{ISOTROPIC RECTANGULAR PLATES SUBJECTED TO NON-UNIFORM HEATING}

\section{Results and discussion}

\subsection{Analysis of rectangular plates simply supported along all edges}

The bending analysis of rectangular plates simply supported along all edges and subjected to a non-uniform heating was conducted. Detailed analysis and results are presented in Appendix A and in the Supplementary Material "Rectangular plates simply supported along all edges." The bending moments (mxx, myy) and displacements $\mathrm{w}$ at the plate center are determined, whereas the twisting moments mxy are determined at plate angles. The results related to the solution of Navier [3] are listed in Table 1 for various aspect ratios a/b and Poisson's ratios, whereby 2500 terms are considered (m, $\mathrm{n}$ odd numbers from 1 to 99). The results related to the solution of Lévy [4] are listed in Table 2 for various aspect ratios a/b and Poisson's ratios, whereby 51 terms are considered (m odd numbers from 1 to 101 ).

Table 1. Bending moments $\mathrm{m}_{\mathrm{xx}}$ and $\mathrm{m}_{\mathrm{yy}}$, twisting moments $\mathrm{m}_{\mathrm{xy}}$, and displacements, using the solution of Navier.

\begin{tabular}{|c|c|c|c|c|c|c|c|c|}
\hline & $\mathbf{a} / \mathbf{b}=$ & 1,00 & 1,50 & 2,00 & 3,00 & 5,00 & 10,00 & 20,00 \\
\hline \multirow{4}{*}{$\begin{array}{l}\text { Poisson's } \\
\text { ratio } v=0.0\end{array}$} & $\mathrm{mxx} / \mathrm{D \kappa} T=$ & -0.49365 & -0.75517 & -0.88390 & -0.97080 & -0.99268 & -0.99367 & -0.99367 \\
\hline & myy / DאT= & -0.49365 & -0.23214 & -0.10341 & -0.01651 & 0.00538 & 0.00636 & 0.00636 \\
\hline & $m x y / D \kappa T=$ & 3.26372 & 3.20110 & 3.09701 & 2.90740 & 2.63519 & 2.23414 & 1.81309 \\
\hline & $\mathrm{w} / \mathrm{b}^{2} \kappa \mathrm{K}=$ & 0.0737 & 0.1008 & 0.1139 & 0.1227 & 0.1249 & 0.1250 & 0.1250 \\
\hline \multirow{4}{*}{$\begin{array}{l}\text { Poisson's } \\
\text { ratio } v=0.20\end{array}$} & $m x x / D \kappa T=$ & -0.47391 & -0.72497 & -0.84854 & -0.93197 & -0.95298 & -0.95393 & -0.95392 \\
\hline & myy / DкT= & -0.47391 & -0.22285 & -0.09928 & -0.01585 & 0.00516 & 0.00611 & 0.00611 \\
\hline & $m x y / D \kappa T=$ & 3.13317 & 3.07306 & 2.97313 & 2.79111 & 2.52978 & 2.14477 & 1.74057 \\
\hline & $w / b^{2} \kappa T=$ & 0.0884 & 0.1209 & 0.1366 & 0.1472 & 0.1499 & 0.1500 & 0.1500 \\
\hline
\end{tabular}

Table 2. Bending moments $\mathrm{m}_{\mathrm{xx}}$ and $\mathrm{m}_{\mathrm{yy}}$, twisting moments $\mathrm{m}_{\mathrm{xy}}$, and displacements, using the solution of Lévy.

\begin{tabular}{|c|c|c|c|c|c|c|c|c|}
\cline { 2 - 9 } \multicolumn{1}{c|}{} & $\mathbf{a} / \mathbf{b}=$ & $\mathbf{1 , 0 0}$ & $\mathbf{1 , 5 0}$ & $\mathbf{2 , 0 0}$ & $\mathbf{3 , 0 0}$ & $\mathbf{5 , 0 0}$ & $\mathbf{1 0 , 0 0}$ & $\mathbf{2 0 , 0 0}$ \\
\hline \multirow{3}{*}{$\begin{array}{c}\text { Poisson's } \\
\text { ratio } v=0.0\end{array}$} & $\mathrm{mxx} / \mathrm{D \kappa} T=$ & -0.5000 & -0.7615 & -0.8902 & -0.9771 & -0.9990 & -1.0000 & -1.0000 \\
\cline { 2 - 9 } & $\mathrm{myy} / \mathrm{D} \mathrm{T} T=$ & -0.5062 & -0.2447 & -0.1160 & -0.0291 & -0.0072 & -0.0062 & -0.0062 \\
\cline { 2 - 9 } & $\mathrm{mxy} / \mathrm{D} \mathrm{T} T=$ & 3.6475 & 3.4723 & 3.3071 & 3.0535 & 2.7285 & 2.2872 & 1.8460 \\
\cline { 2 - 9 } & $\mathrm{w} / \mathrm{b}^{2} \kappa \mathrm{K}=$ & 0.0737 & 0.1008 & 0.1139 & 0.1227 & 0.1249 & 0.1250 & 0.1250 \\
\hline
\end{tabular}

It was noted that the double trigonometric series converges slowly. For high values of $\mathrm{a} / \mathrm{b}$ and far from the edges $\mathrm{x}=0$ and $\mathrm{x}=\mathrm{a}$, the plate has a beam-like behavior in $\mathrm{y}$-direction and $\partial^{2} \mathrm{w} / \partial \mathrm{x}^{2}=0$. According to classical beam theory (CBT), the deflection at the center of the beam is $\kappa_{\mathrm{T}} \mathrm{b}^{2} / 8$. Given Poisson's ratio = zero, the results for bending moment $\operatorname{mxx}($ Equation (5a)) and deflection at the plate center are in good agreement with CBT. 


\subsection{Analysis of rectangular plates simply supported along $\mathrm{x}=0$ and $\mathrm{x}=\mathrm{a}$}

The solution of Lévy was applied at the deflection curve. Detailed analysis and results are presented in the Supplementary Material "Rectangular plates simply supported along two opposite edges and having various support conditions along other edges." The bending moments are determined at the plate center (mxx, myy) and at mid-spans of the free edge (mxx,fr) / fixed edge (myy,fe), and the displacements are determined at the plate center and at mid-span of the free edge. The results are listed in Table 3 for various support conditions, aspect ratios a/b, and Poisson's ratios.

Table 3. Bending moments mxx, myy, and mxx,fr, and displacements.

\begin{tabular}{|c|c|c|c|c|c|c|c|c|}
\hline & $\mathbf{a} / \mathbf{b}=$ & 0.50 & 0.75 & 1.00 & 2.00 & 5.00 & 10.00 & 20.00 \\
\hline \multicolumn{9}{|c|}{ Edges $x=0$ and $x=$ a simply supported (SS), edge $y=b / 2$ fixed, and edge $y=-b / 2$ SS } \\
\hline \multirow{4}{*}{$\begin{array}{l}\text { Poisson's } \\
\text { ratio } v=0.0\end{array}$} & $m x x / D \kappa T=$ & -0.2807 & -0.6079 & -0.8248 & -1.0203 & -1.0002 & -1.0000 & -1.0015 \\
\hline & myy / DкT= & -0.8414 & -0.7039 & -0.6553 & -0.7169 & -0.7627 & -0.7627 & -0.7617 \\
\hline & myy,fe / DкT= & -2.0162 & -1.9578 & -1.8618 & -1.5965 & -1.5254 & -1.5255 & -1.5254 \\
\hline & $w / b^{2} \kappa T=$ & 0.0241 & 0.0353 & 0.0392 & 0.0348 & 0.0313 & 0.0313 & 0.0314 \\
\hline \multirow{4}{*}{$\begin{array}{l}\text { Poisson's } \\
\text { ratio } v=0.20\end{array}$} & $m x x / D \kappa T=$ & -0.2957 & -0.6554 & -0.9040 & -1.1534 & -1.1402 & -1.1400 & -1.1415 \\
\hline & myy / DкT= & -0.8340 & -0.7476 & -0.7413 & -0.8621 & -0.9123 & -0.9122 & -0.9114 \\
\hline & myy,fe / DкT= & -2.4194 & -2.3494 & -2.2342 & -1.9158 & -1.8304 & -1.8305 & -1.8305 \\
\hline & $w / b^{2} \kappa T=$ & 0.0290 & 0.0424 & 0.0471 & 0.0417 & 0.0375 & 0.0376 & 0.0377 \\
\hline \multicolumn{9}{|c|}{ Edges $x=0$ and $x=a$ simply supported, edge $y=b / 2$ fixed, and edge $y=-b / 2$ free } \\
\hline \multirow{5}{*}{$\begin{array}{l}\text { Poisson's } \\
\text { ratio } v=0.0\end{array}$} & $m x x / D \kappa T=$ & -0.1914 & -0.4556 & -0.6975 & -1.1099 & -1.0367 & -1.0017 & -1.0010 \\
\hline & myy / DкT= & -0.8962 & -0.7867 & -0.7261 & -0.6175 & -0.1616 & -0.0204 & -0.0121 \\
\hline & myy,fe / DкT= & -2.0385 & -2.0662 & -2.0327 & -1.3459 & -0.2174 & -0.0350 & -0.0255 \\
\hline & $m x x, f r / D \kappa T=$ & -0.3640 & -0.4999 & -0.7190 & -1.3053 & -1.1228 & -1.0102 & -1.0043 \\
\hline & $w / b^{2} \kappa T=$ & 0.0202 & 0.0376 & 0.0446 & -0.0709 & -0.4176 & -0.4958 & -0.4999 \\
\hline \multirow{5}{*}{$\begin{array}{c}\text { Poisson's } \\
\text { ratio } v=0.20\end{array}$} & $m x x / D \kappa T=$ & -0.2190 & -0.5218 & -0.7968 & -1.2438 & -1.0275 & -0.9616 & -0.9611 \\
\hline & myy / DкT= & -0.8736 & -0.8087 & -0.7958 & -0.7173 & -0.1420 & -0.0154 & -0.0116 \\
\hline & myy,fe / DкT= & -2.4409 & -2.4545 & -2.3951 & -1.5161 & -0.1764 & -0.0336 & -0.0306 \\
\hline & $m x x, f r / D \kappa T=$ & -0.2732 & -0.4310 & -0.6881 & -1.3778 & -1.0956 & -0.9664 & -0.9631 \\
\hline & $w / b^{2} \kappa T=$ & 0.0226 & 0.0416 & 0.0467 & -0.1185 & -0.5344 & -0.5984 & -0.5998 \\
\hline \multicolumn{9}{|c|}{ Edges $x=0, x=a$, and $y=b / 2$ simply supported, and edge $y=-b / 2$ free } \\
\hline \multirow{4}{*}{$\begin{array}{l}\text { Poisson's } \\
\text { ratio } v=0.0\end{array}$} & $m \times x / D \kappa T=$ & -0.0163 & -0.1085 & -0.2444 & -0.7160 & -0.9929 & -1.0000 & -1.0000 \\
\hline & myy / DкT= & -0.9599 & -0.8051 & -0.6175 & -0.1432 & -0.0075 & -0.0127 & -0.0126 \\
\hline & $m x x, f r / D \kappa T=$ & -0.3408 & -0.3644 & -0.4168 & -0.7132 & -0.9906 & -1.0042 & -1.0042 \\
\hline & $\mathrm{w} / \mathrm{b}^{2} \kappa \mathrm{T}=$ & 0.0208 & 0.0453 & 0.0753 & 0.1793 & 0.2477 & 0.2500 & 0.2501 \\
\hline
\end{tabular}




\section{ISOTROPIC RECTANGULAR PLATES SUBJECTED TO NON-UNIFORM HEATING}

\begin{tabular}{|l|c|c|c|c|c|c|c|c|}
\hline \multirow{3}{*}{$\begin{array}{l}\text { Poisson's } \\
\text { ratio } v=0.20\end{array}$} & $\mathrm{mxx} / \mathrm{D} \mathrm{T} T=$ & -0.0250 & -0.1161 & -0.2412 & -0.6692 & -0.9480 & -0.9600 & -0.9601 \\
\cline { 2 - 9 } & $\mathrm{myy} / \mathrm{D} \mathrm{T}=$ & -0.9079 & -0.7490 & -0.5678 & -0.1332 & -0.0086 & -0.0122 & -0.0120 \\
\cline { 2 - 9 } & $\mathrm{mxx}, \mathrm{fr} / \mathrm{D} \mathrm{T}=$ & -0.2465 & -0.2717 & -0.3270 & -0.6381 & -0.9442 & -0.9630 & -0.9631 \\
\cline { 2 - 9 } & $\mathrm{w} / \mathrm{b}^{2} \mathrm{~K} T=$ & 0.0233 & 0.0510 & 0.0849 & 0.2062 & 0.2955 & 0.3000 & 0.3002 \\
\hline
\end{tabular}

For high values of $\mathrm{a} / \mathrm{b}$ and far from the edges $\mathrm{x}=0$ and $\mathrm{x}=\mathrm{a}$, the plate has a beam-like behavior in $\mathrm{y}$-direction and $\partial^{2} w / \partial x^{2}=0$. Let us consider the plate having fixed-pinned edges in $y$-direction $(y= \pm b / 2)$; according to CBT , the bending moments myy at the fixed end and at mid-span of the corresponding beam are $-1.5 \times \mathrm{D} \kappa_{\mathrm{T}}$ and $-0.75 \times \mathrm{D} \kappa_{\mathrm{T}}$, respectively. Given Poisson's ratio = zero, the results for bending moment myy are in good agreement with CBT. For a plate having fixed-free edges in $y$-direction $(y= \pm b / 2)$, the deflection at the free end of the corresponding beam according to CBT is $-\kappa_{\mathrm{T}} \mathrm{b}^{2} / 2$. Given Poisson's ratio = zero, the results for bending moment mxx (Equation (5a)) and deflection at free end are in good agreement with CBT.

\subsection{Analysis of rectangular plates simply supported at $x=0$ and $x=a$, and having identical support conditions along $\mathrm{y}= \pm \mathrm{b} / 2$}

The solution of Lévy was applied at the deflection curve. Detailed analysis and results are presented in Appendix B, Appendix C, and in the Supplementary Material "Rectangular plates simply supported along two opposite edges and having identical support conditions along other edges." The edges $\mathrm{x}=\mathrm{o}$ and $\mathrm{x}=\mathrm{a}$ are simply supported, the other edges are both fixed or both free. The bending moments are determined at the plate center (mxx, myy) and at mid-spans of the free edge (mxx,fr) / fixed edge (myy,fe), and the displacements are determined at the plate center and at mid-span of the free edge. The results are listed in Table 4 for various support conditions, aspect ratios a/b, and Poisson's ratios.

Table 4. Bending moments mxx, myy, and mxx,fe, and displacements.

\begin{tabular}{|c|c|c|c|c|c|c|c|c|}
\hline & $\mathbf{a} / \mathbf{b}=$ & 0.50 & 0.75 & 1.00 & 2.00 & 5.00 & 10.00 & 20.00 \\
\hline \multicolumn{9}{|c|}{ Edges $x=0$ and $x=a$ simply supported, and edges $y= \pm b / 2$ fixed } \\
\hline \multirow{4}{*}{$\begin{array}{l}\text { Poisson's } \\
\text { ratio } v=0.0\end{array}$} & $m x x / D \kappa T=$ & -0.4450 & -0.8544 & -1.0403 & -1.0467 & -0.9999 & -1.0000 & -1.0000 \\
\hline & myy / DкT= & -0.7631 & -0.6843 & -0.7363 & -0.9599 & -0.9937 & -0.9936 & -0.9937 \\
\hline & myy, fe / DкT= & -1.9289 & -1.7002 & -1.4440 & -1.0175 & -0.9872 & -0.9873 & -0.9873 \\
\hline & $w / b^{2} \kappa T=$ & 0.0200 & 0.0210 & 0.0158 & 0.0017 & 0.0000 & 0.0000 & 0.0000 \\
\hline \multirow{4}{*}{$\begin{array}{l}\text { Poisson's } \\
\text { ratio } v=0.20\end{array}$} & $m x x / D \kappa T=$ & -0.4787 & -0.9510 & -1.1866 & -1.2479 & -1.1999 & -1.2000 & -1.2000 \\
\hline & myy / DкT= & -0.7841 & -0.7877 & -0.8948 & -1.1646 & -1.1939 & -1.1939 & -1.1939 \\
\hline & myy,fe / DкT= & -2.3147 & -2.0403 & -1.7328 & -1.2210 & -1.1847 & -1.1847 & -1.1847 \\
\hline & $w / b^{2} \kappa T=$ & 0.0240 & 0.0253 & 0.0190 & 0.0020 & 0.0000 & 0.0000 & 0.0000 \\
\hline
\end{tabular}


ISOTROPIC RECTANGULAR PLATES SUBJECTED TO NON-UNIFORM HEATING

\begin{tabular}{|c|c|c|c|c|c|c|c|c|}
\hline \multicolumn{9}{|c|}{ Edges $x=0$ and $x=a$ simply supported, and edges $y= \pm b / 2$ free } \\
\hline \multirow{4}{*}{$\begin{array}{l}\text { Poisson's } \\
\text { ratio } v=0.0\end{array}$} & $m x x / D \kappa T=$ & 0.0793 & 0.1219 & 0.1236 & 0.0517 & 0.0017 & 0.0000 & 0.0000 \\
\hline & myy / DкT= & -0.9991 & -0.9015 & -0.7501 & -0.2646 & -0.0026 & 0.0063 & 0.0064 \\
\hline & $m x x, f r / D \kappa T=$ & -0.3245 & -0.2937 & -0.2467 & -0.0891 & -0.0009 & 0.0021 & 0.0021 \\
\hline & $w / a^{2} \kappa T=$ & 0.1330 & 0.1376 & 0.1383 & 0.1329 & 0.1267 & 0.1254 & 0.1251 \\
\hline \multirow{4}{*}{$\begin{array}{l}\text { Poisson's } \\
\text { ratio } v=0.20\end{array}$} & $m \times x / D \kappa T=$ & 0.0570 & 0.0868 & 0.0866 & 0.0334 & 0.0008 & 0.0000 & 0.0000 \\
\hline & myy / DkT= & -0.9313 & -0.8121 & -0.6539 & -0.2051 & 0.0009 & 0.0061 & 0.0061 \\
\hline & $m x x, f r / D \kappa T=$ & -0.2331 & -0.2084 & -0.1717 & -0.0562 & 0.0001 & 0.0015 & 0.0015 \\
\hline & $\mathrm{w} / \mathrm{a}^{2} \kappa \mathrm{K}=$ & 0.1556 & 0.1564 & 0.1534 & 0.1391 & 0.1278 & 0.1257 & 0.1252 \\
\hline
\end{tabular}

For the fixed-fixed plate in $y$-direction $(y= \pm b / 2)$, high values of $a / b$ and far from the edges $x=0$ and $x=a$, the plate has a beam-like behavior in $\mathrm{y}$-direction and $\partial^{2} \mathrm{w} / \partial \mathrm{x}^{2}=0$. The deflection curve of the corresponding beam according to CBT is zero throughout the beam; the results for bending moments mxx and myy (Equation (5a-b)) and deflection are in good agreement with CBT. For the free-free plate in $y$-direction $(y= \pm b / 2)$, high values of a/b and far from the edges $\mathrm{x}=0$ and $\mathrm{x}=\mathrm{a}$, the plate has a beam-like behavior in $\mathrm{x}$-direction and the deflection at the center of the corresponding beam according to CBT is $\kappa_{\mathrm{Ta}} \mathrm{a}^{2} / 8$; the deflection results are in good agreement with CBT.

\section{Conclusion}

The bending analysis of isotropic rectangular Kirchhoff plates subjected to a non-uniform heating (NUH) was conducted in this paper. The temperature changes were assumed to vary linearly through the plate thickness. The NUH was transformed using Fourier series; simple and double trigonometric series were considered. The deflection curve was formulated using the double trigonometric series of Navier and the simple trigonometric series of Lévy. Rectangular plates simply supported along all edges were analyzed, as well as those simply supported along two opposite edges. Bending moments, twisting moments, and deflections were determined. Numerical results were presented, and for high aspect ratios those results were in good agreement with those of the classical beam theory.

The following aspect was not addressed in this study but could be analyzed in the future:

Rectangular anisotropic plate

Supplementary Materials: The following files were uploaded during submission:

- "Rectangular plates simply supported along all edges"

- $\quad$ "Rectangular plates simply supported along two opposite edges and having various support conditions along other edges"

- $\quad$ "Rectangular plates simply supported along two opposite edges and having identical support conditions along other edges." 


\section{Funding:}

\section{Acknowledgments:}

Conflicts of Interest: The author declares no conflict of interest.

\section{Appendix A: Rectangular plates simply supported along all edges}

The double trigonometric series of Navier was considered. The bending moments at the plate center, the twisting moments at the angles, and the displacement at the plate center, were calculated using Equations (12a-b), Equation (12c), and Equation (11b), respectively.

$$
\begin{aligned}
& m_{x x}\left(x=\frac{a}{2}, y=\frac{b}{2}\right)=\frac{16(1+v)}{\pi^{2}} D \kappa_{T} \times \sum_{m} \sum_{n} \frac{1}{m n}\left[\frac{m^{2}+v(n a / b)^{2}}{m^{2}+(n a / b)^{2}}-1\right] \sin \frac{m \pi}{2} \sin \frac{n \pi}{2} \\
& m_{y y}\left(x=\frac{a}{2}, y=\frac{b}{2}\right)=\frac{16(1+v)}{\pi^{2}} D \kappa_{T} \times \sum_{m} \sum_{n} \frac{1}{m n}\left[\frac{v m^{2}+(n a / b)^{2}}{m^{2}+(n a / b)^{2}}-1\right] \sin \frac{m \pi}{2} \sin \frac{n \pi}{2} \\
& m_{x y}= \pm \frac{16\left(1-v^{2}\right)}{\pi^{2}} D \kappa_{T} \times \sum_{m} \sum_{n} \frac{1}{m^{2} \frac{b}{a}+n^{2} \frac{a}{b}} \\
& w\left(x=\frac{a}{2}, y=\frac{b}{2}\right)=\frac{16 a^{2}(1+v) \kappa_{T}}{\pi^{4}} \sum_{m} \sum_{n} \frac{1}{m n} \frac{1}{m^{2}+(n a / b)^{2}} \sin \frac{m \pi}{2} \sin \frac{n \pi}{2}
\end{aligned}
$$

The simple trigonometric series of Lévy was also considered. For simplification purpose the origin of the y-axis was shifted to the middle of the plate, so that the edges were at $y= \pm b / 2$. The satisfaction of the boundary conditions yields:

$$
A_{m}=-\frac{\kappa_{T m}}{\alpha_{m}^{2} \operatorname{ch} \alpha_{m} \frac{b}{2}} \quad B_{m}=C_{m}=D_{m}=0 \text {. }
$$

The bending moments at the plate center, the twisting moments at the angles, and the displacement at the plate center, were calculated using Equations (19a-b), (A5-6), Equations (19c), (A5-6), and Equations (13), (14b), (16a-b), and (A56), respectively.

$$
\begin{aligned}
& m_{x x}\left(x=\frac{a}{2}, y=0\right)=-\frac{4\left(1-v^{2}\right)}{\pi} D \kappa_{T} \times \sum_{m} \frac{1}{m} \frac{1}{c h \alpha_{m} b / 2} \sin \frac{m \pi}{2} \\
& m_{y y}\left(x=\frac{a}{2}, y=0\right)=-\frac{4\left(1-v^{2}\right)}{\pi} D \kappa_{T} \times \sum_{m}\left(1-\frac{1}{c h \alpha_{m} b / 2}\right) \frac{1}{m} \sin \frac{m \pi}{2}
\end{aligned}
$$




$$
\begin{aligned}
m_{x y}\left(x=0, y=\frac{b}{2}\right) & =\frac{4\left(1-v^{2}\right)}{\pi} D \kappa_{T} \times \sum_{m} \frac{1}{m} \tan \alpha_{m} b / 2 \\
w\left(x=\frac{a}{2}, y=0\right) & =\frac{4 a^{2}(1+v) \kappa_{T}}{\pi^{3}} \sum_{m}\left(1-\frac{1}{c h \alpha_{m} b / 2}\right) \frac{1}{m^{3}} \sin \frac{m \pi}{2} \\
& =\frac{4 b^{2}(1+v) \kappa_{T}}{\pi^{3}} \frac{a^{2}}{b^{2}} \sum_{m}\left(1-\frac{1}{c h \alpha_{m} b / 2}\right) \frac{1}{m^{3}} \sin \frac{m \pi}{2}
\end{aligned}
$$

\section{Appendix B: Rectangular plate simply supported along $x=0$ and $x=a$, and fixed along $y= \pm b / 2$}

The simple trigonometric series of Lévy was considered. The origin of the y-axis was shifted to the middle of the plate, so that the plate edges were at $y= \pm b / 2$. The satisfaction of the boundary conditions yields:

$$
\begin{aligned}
& A_{m}=-\frac{s h \alpha_{m} b / 2+\alpha_{m} b / 2 \times \operatorname{ch} \alpha_{m} b / 2}{s h \alpha_{m} b / 2 \times \operatorname{ch} \alpha_{m} b / 2+\alpha_{m} b / 2} \times \frac{\kappa_{T m}}{\alpha_{m}^{2}} \\
& B_{m}=\frac{s h \alpha_{m} b / 2}{s h \alpha_{m} b / 2 \times \operatorname{ch} \alpha_{m} b / 2+\alpha_{m} b / 2} \times \frac{\kappa_{T m}}{\alpha_{m}^{2}} \quad C_{m}=D_{m}=0
\end{aligned}
$$

The bending moments at plate center/mid-span of the fixed edge, and the displacement at the plate center were calculated using Equations (19a-b), (B1-3), and Equations (13), (14b), and (16a-b), respectively.

$$
\begin{aligned}
& m_{x x}\left(x=\frac{a}{2}, y=0\right)=\frac{4\left(1-v^{2}\right)}{\pi} D \kappa_{T} \times \sum_{m} \frac{1}{m}\left[\frac{-\alpha_{m} b / 2 \times \operatorname{ch} \alpha_{m} b / 2+s h \alpha_{m} b / 2 \times(1-2 /(1-v))}{s h \alpha_{m} b / 2 \times \operatorname{ch} \alpha_{m} b / 2+\alpha_{m} b / 2}\right] \sin \frac{m \pi}{2} \\
& m_{y y}\left(x=\frac{a}{2}, y=0\right)=-\frac{4\left(1-v^{2}\right)}{\pi} D \kappa_{T} \times \sum_{m} \frac{1}{m}\left[\frac{-\alpha_{m} b / 2 \times \operatorname{ch} \alpha_{m} b / 2+\operatorname{sh} \alpha_{m} b / 2 \times(1+2 v /(1-v))}{\operatorname{sh} \alpha_{m} b / 2 \times \operatorname{ch} \alpha_{m} b / 2+\alpha_{m} b / 2}+1\right] \sin \frac{m \pi}{2} \\
& m_{y y}\left(x=\frac{a}{2}, y=\frac{b}{2}\right)=-D \times \sum_{m} \alpha_{m}^{2}(1-v)\left[A_{m} \operatorname{ch} \alpha_{m} \frac{b}{2}+B_{m}\left(\frac{2}{1-v} \operatorname{ch} \alpha_{m} \frac{b}{2}+\alpha_{m} \frac{b}{2} \times \operatorname{sh} \alpha_{m} \frac{b}{2}\right)+\frac{\kappa_{T m}}{\alpha_{m}^{2}}\right] \sin \frac{m \pi}{2} \\
& w\left(x=\frac{a}{2}, y=0\right)=\frac{4 a^{2}(1+v) \kappa_{T}}{\pi^{3}} \sum_{m} \frac{1}{m^{3}}\left(1-\frac{\operatorname{sh} \alpha_{m} b / 2+\alpha_{m} b / 2 \times \operatorname{ch} \alpha_{m} b / 2}{\operatorname{sh} \alpha_{m} b / 2 \times \operatorname{ch} \alpha_{m} b / 2+\alpha_{m} b / 2}\right) \sin \frac{m \pi}{2}
\end{aligned}
$$




\section{Appendix C: Rectangular plate simply supported along $x=0$ and $x=a$, and free along $y= \pm b / 2$}

The simple trigonometric series of Lévy was considered. The origin of the y-axis was shifted to the middle of the plate, so that the plate edges were at $y= \pm b / 2$. The satisfaction of the boundary conditions yields:

$$
\begin{aligned}
& A_{m}=-\frac{(1+v) \operatorname{sh} \alpha_{m} b / 2-(1-v) \alpha_{m} b / 2 \times c h \alpha_{m} b / 2}{(3+v) \operatorname{sh} \alpha_{m} b / 2 \times \operatorname{ch} \alpha_{m} b / 2-(1-v) \alpha_{m} b / 2} \times \frac{\kappa_{T m}}{\alpha_{m}^{2}} \\
& B_{m}=-\frac{(1-v) \operatorname{sh} \alpha_{m} b / 2}{(3+v) \operatorname{sh} \alpha_{m} b / 2 \times \operatorname{ch} \alpha_{m} b / 2-(1-v) \alpha_{m} b / 2} \times \frac{\kappa_{T m}}{\alpha_{m}^{2}} \quad C_{m}=D_{m}=0
\end{aligned}
$$

The bending moments at plate center/free edge, and the displacement at the plate center were calculated using Equations (19a-b), (C1-3), and Equations (13), (14b), (16a-b), and (C1-3), respectively, as follows:

$$
\begin{aligned}
& m_{x x}\left(x=\frac{a}{2}, y=0\right)=-D \times \sum_{m} \alpha_{m}^{2}(v-1)\left[A_{m}+B_{m} \frac{2 v}{v-1}\right] \sin \frac{m \pi}{2} \\
& m_{y y}\left(x=\frac{a}{2}, y=0\right)=-D \times \sum_{m} \alpha_{m}^{2}(1-v)\left[A_{m}+B_{m} \frac{2}{1-v}+\frac{\kappa_{T m}}{\alpha_{m}^{2}}\right] \sin \frac{m \pi}{2} \\
& m_{x x}\left(x=\frac{a}{2}, y=\frac{b}{2}\right)=-D \times \sum_{m} \alpha_{m}^{2}(v-1)\left[A_{m} \operatorname{ch} \alpha_{m} \frac{b}{2}+B_{m}\left(\frac{2 v}{v-1} \operatorname{ch} \alpha_{m} \frac{b}{2}+\alpha_{m} \frac{b}{2} \times \operatorname{sh} \alpha_{m} \frac{b}{2}\right)\right] \sin \frac{m \pi}{2} \\
& w\left(x=\frac{a}{2}, y=0\right)=\sum_{m}\left(A_{m}+\frac{\kappa_{T m}}{\alpha_{m}^{2}}\right) \sin \frac{m \pi}{2}
\end{aligned}
$$

\section{References}

[1] Kirchhoff, G. Über das Gleichgewicht und die Bewegung einer elastischen Scheibe. J. für die Reine und Angew. Math.; vol. 18, no. 40, pp. 51-88, 1850.

[2] Germain, S. Remarques sur la nature, les bornes et l'étendue de la question des surfaces élastiques et équation générale de ces surfaces. impr. de Huzard-Courcier, paris, 1826.

[3] Navier, C.L. Extrait des recherches sur la flexion des plaques élastiques. Bull. des Sci. Société Philomath, Paris, vol. 10, no. 1, pp. 92-102, 1823. 
[4] Lévy, M. Sur l'équilibre élastique d'une plaque rectangulaire. Comptes rendus l'Académie des Sci. Paris, vol. 129, no. 1, pp. 535-539, 1899.

[5] Mama, B.O., Nwoji, C.U., Ike, C.C., Onah, H.N. Analysis of Simply Supported Rectangular Kirchhoff Plates by the Finite Fourier Sine Transform Method. IJAERS, Vol-4, Issue-3, Mar- 2017 https://dx.doi.org/10.22161/ijaers.4.3.44

[6] Kamel, A-K. Finite Fourier transform for solving potential and steady-state temperature problems. Advances in Difference Equations (2018), 2018:98. https://doi.org/10.1186/s13662-018-1552-8

[7] Mama, B.O., Oguaghamba, O.A., Ike, C.C. Single Finite Fourier Sine Integral Transform Method for the Flexural Analysis of Rectangular Kirchhoff Plate with Opposite Edges Simply Supported, Other Edges Clamped for the Case of Triangular Load Distribution. IJERT, Vol. 13, 7 (2020), pp. 1802-1813.

DOI: $10.37624 /$ IJERT/13.7.2020.1802-1813

[8] Sayyad, A.S., Ghugal Y.M. Bending of shear deformable plates resting on Winkler foundations according to trigonometric plate theory. J. Appl. Comput. Mech., 4(3) (2018) 187-201. DOI: 10.22055/JACM.2017.23057.1148

[9] Onyia, M.E., Rowland-Lato, E.O., Ike, C.C. Elastic buckling analysis of SSCF and SSSS rectangular thin plates using the single finite Fourier sine integral transform method. IJERT, Vol 13, No 6, pp 1147 - 1158, july 2020. DOI: 10.37624/IJERT/13.6.2020.1147-1158

[10] Ike, C.C. Double Fourier cosine series method for the flexural analysis of Kirchhoff plates on Winkler foundations. Journal of Geotechnical and Transportation Engineering, Vol 4, Issue 2, pp 30 - 38, december 2018 